\title{
APPLICATION OF HYDRAULIC AUTOMATION EQUIPMENT FOR THE EFFICIENCY ENHANCEMENT OF THE OPERATION ELEMENTS OF THE MOBILE MACHINERY
}

\author{
Leonid Polishchuk $^{1}$, Leonid Kozlov ${ }^{1}$, Yuri Burennikov ${ }^{1}$, Vasil Strutinskiy ${ }^{2}$, Valerii Kravchuk ${ }^{1}$ \\ ${ }^{\mathrm{I} V i n n y t s i a}$ National Technical University, ${ }^{2}$ National Technical University of Ukraine "Igor Sikorsky Kyiv Polytechnic institute"
}

Abstract: The application of adaptive drives in working units of various technological and mobile machines is considered. The results of theoretical and experimental research have proved the effectiveness of their use for improving the dynamic characteristics of machines, reducing unproductive power losses during their operation.

Keywords: hydroautomatics, tools, workstations, mobile machines

\section{ZASTOSOWANIE WYPOSAŻENIA AUTOMATYZACJI HYDRAULICZNEJ W CELU POPRAWY EFEKTYWNOŚCI ELEMENTÓW OPERACYJNYCH MASZYN MOBILNYCH}

\begin{abstract}
Streszczenie. $W$ pracy rozważane jest zastosowanie napędów adaptacyjnych $w$ jednostkach roboczych różnych maszyn technologicznych $i$ mobilnych Skuteczność zastosowania tych algorytmów do poprawy charakterystyk dynamicznych maszyn, przy jednoczesnym zmniejszeniu nieproduktywnych strat mocy podczas pracy potwierdzity wyniki badań teoretycznych i eksperymentalnych.
\end{abstract}

Slowakluczowe: hydraulika, narzędzia, stacje robocze, maszyny mobilne

\section{Introduction}

Greater parts of the mechanisms of various technological designation operate in variable loads mode. In particular, in civil engineering and industry mobile working mechanisms with the manipulators on the base of trucks and wheeled tractors, equipped with various movable working tools are widely used. The operation of the manipulators of the mechanisms with movableworking tools to provide optimal performing of the operation requires the proportion regulation of the working fluid consumption, supplied from the pump to the hydraulic motor which is not available in the mobile mechanisms, manufactured in our country andabroad.

Variable loads in the drive systems of the conveyors occur as a result of the irregularity of the load flows, arrived on the conveyor belts of the mobile mechanisms, for instance, clamp formers, beet harvesting machines, etc. This stipulates the onset of the mechanical oscillations, creating the conditions for the fatigue failure of the belt, parts and units of the mechanism. The solution of these problems requires the application of new drive constructions with the automatic adaptation of their parameters to variable operation modes. It enables to provide the decrease of the dynamic efforts in the elements of the drives construction and executive elements, decrease of the unproductive power losses in the process of their operation

\section{Analysis of the hydraulicautomatic equipment application for the technological machines with variable loading modes}

The development of the hydraulic drives of the mobile and technological machines is accompanied by the wide application of the proportional hydraulic equipment andregulated pumps. Stable trend is the transition to the hydraulics drives, sensitive to loading $[4,5]$. Application in such hydraulic drives of the equipment and pumps with the electrohydraulic control enables to improve the accuracy of the machines with hydraulic drive operation, decrease the unproductive power losses [21, 24].Usage of the hydraulic equipment with electric hydraulic control enables to apply in the hydraulic systems of the last generation freely programmable controllers and providesemiautomatic and automatic operation of modern machines $[2,8,11]$. The controllers, available in the adaptive hydraulic drives allow to realize the adaptive control of the machine, that enables of improve considerably static, dynamic and energy characteristics of the machines, adapt their operation modes to the constantly changing conditions in the process of the operation $[12,23]$.

Variable operation modes are also common for the mobile complexes, used in the process of the surface mining of the minerals resources or sugar beet clamping at the sugar mills.

Efficiency factor of the conveyors usage at mining enterprises is, on average, $50 \ldots 70 \%$ by power and $60 . .70 \%$ by the operation duration [22]. Such inefficient usage of the conveyors is connected with the irregular load flows by the amplitude of the loading and interruptions in load supply, etc. These operation modes of the conveyor cause unjustified energy losses, belt and conveyor rollers wear, increase of the no-load run of the belt, down time of the equipment. That is why, greater part of the research $[1,13,25$, $26]$ is directed at the provision of the coordination of the belt conveyor drive operation modes with the parameters of the load flows by means of belt motion speed control and drum torque.

To provide the continuous operation of the belt conveyors drives, mobile complexes are equipped with and increase their production efficiency it is expedient to apply in the drive the additional hydraulic motor, installed in parallel with the main motor and enables to realize the active reservation of the torque at the drive drum. To switch on the drive it is necessary to install the hydroautomatic devices, sensitive to the load variations on the working organ. The solution of such problems is considered in $[3$, $6,7,16]$. However, the suggested methods and control devices require both the technical improvement and theoretical substantiation of their parameters, which will provide the efficient operation of the device in non-stationary operation modes. This problem requires more detailed study and substantial analysis of the dynamic processes, occurring in the conveyors drives with devices or controlystems.

\section{Hydraulic automatic devices for the operation elements of the mobile machines with variable loads}

In the adaptive hydraulic drive of the manipulator for the trucks and working machines of different designation the regulated pump 1 with the regulator 6 , proportional hydraulic distribution valve 2 , freely programmable controller 3 and sensor 9, 10 (Fig. 1) are used.

Adaptive hydraulic drive provides the operation of the execution mechanism of the machine with trivialpower losses. Proportional control of the hydraulic cylinder provides the possibility to minimize the amount of the manipulator motions to the object, that increases the performance of the machine and quality of the executed work. 


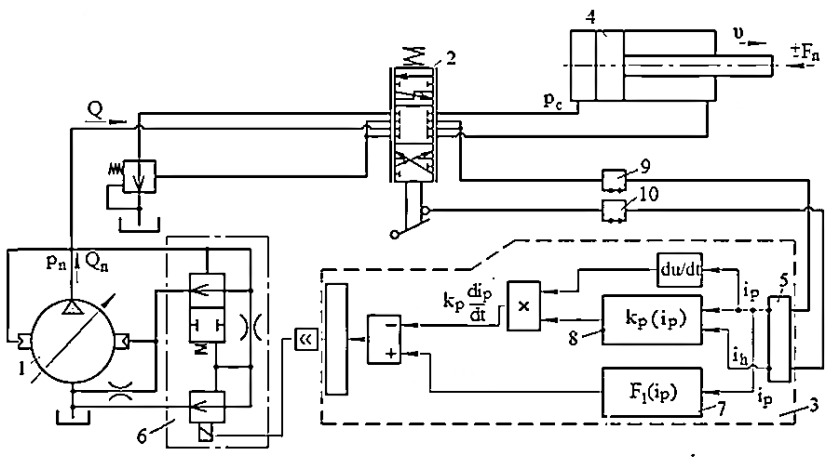

Fig. 1. Adaptive hydraulic drive of the manipulator

Freely programmable controller 3 performs the function of the adaptive regulator, changing the adjustment of the hydraulic drive when the external conditions of its operation change.

Adaptive regulator contains the switching unit 5, feedback unit 7 , and correction unit 8 . Feedback unit provides the transfer of the signals from the hydraulic cylinder to the regulator of the regulated pump. Unit of the feedback signal correction provides the suppression of the oscillations in the hydraulic drive in the transient processes. Feedback signal correction is realized by means of the addition to it the component $\Delta p_{\mathrm{c}}=-k_{\mathrm{p}} \frac{d i_{p}}{d t} . k_{p}$ is the coefficient of the correction component of the adaptive regulator signal, $\mathrm{di}_{\mathrm{p}} / \mathrm{dt}-$ is the derivative from the feedback signal The value of the $\mathrm{k}_{\mathrm{r}}$ coefficient greatly influences the quality of the transient processes in the adaptive hydraulic drive. The modeling of the hydraulic drive operation with the adaptive regulation is carried according to the mathematical model [10, 12].

In the adaptive hydraulic drive of the small-size mobile drilling installation (Fig. 2) regulated pump 1, hydraulic motor 2 of the main motion of the tool, hydraulic cylinder 3 of the tool supply, regulated throttle valves 4 and 5 with the electromagnetic control, controller 6 , valve 7 , hydraulic distribution valves 8,9 , and sensors $10,11,12,13$ are used.

Hydraulic drive operates in two modes. In the first mode both branches of the hydraulic drive operate independently. Pump 1 provides the motion of the hydraulic motor 2 and hydraulic cylinder 3 in the independent speed modes.

In the second mode the adaptive regulator 6 provides the coordinated operation of the hydraulic motor 2 and the hydraulic cylinder 3 . When the load changes at the hydraulic motor $\mathbf{M}_{1}$, the adaptive regulator changes the value of the supply $v_{2}$ of the tool in accordance with the algorithm, which is determined by the program of the controller.

When the value of the pressure $\mathrm{p}_{1}$, which is determined by the value of the moment $\mathrm{M}$ on the hydraulic motor increases, the speed $v_{2}$ of the hydraulic cylinder 3 piston motion proportionally decreases. When the pressure value $p_{c 1}$ deceases, the speed value $v_{2}$ increases.

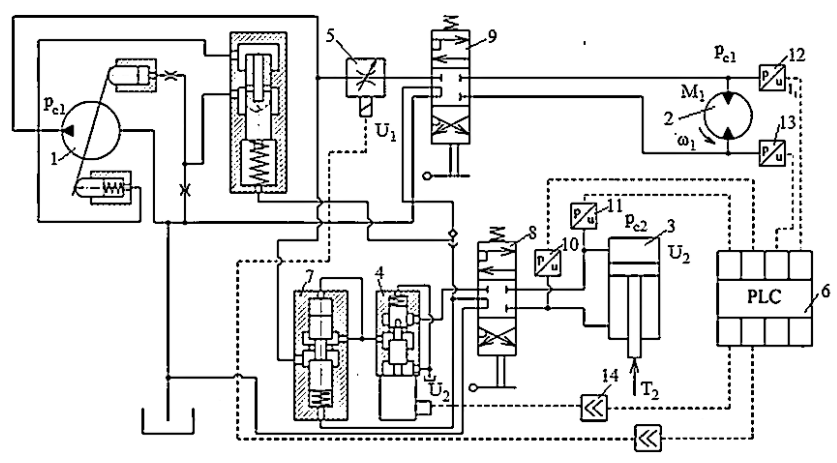

Fig. 2. Adaptive hydraulic drive for the small-size drilling installation

This process is provided by the controller 6 which realizes the cross-coupling in the hydraulic drive. Simulation of the adaptive hydraulic drive operation using the model presented in [9] was carried out. In case of the step-by-step change of the moment $M_{1}$ value from $200 \mathrm{Nm}$ to $800 \mathrm{Nm}$ (Fig. 3) the transient process in the branch, which feeds the hydraulic cylinder 3 passes more dynamically with the readjustments by the value of the pressure $\mathrm{p}_{\mathrm{c} 2}$.

It is possible to decrease the negative impact of the crosscoupling on the dynamic characteristics of the adaptive hydraulic drive as a result of the introduction of the correction of the crosscoupling signal. Such correction is provided by the controller, which changes the cross coupling signal by the necessary law. It is suggested to form the cross-coupling signal as $U_{2}=k_{\mathrm{c}}\left(p_{\mathrm{c} 1}-\right.$ $\left.k_{\mathrm{p}} \frac{d \mathrm{p}_{\mathrm{c} 1}}{d t}\right)$. The following denotations are used: $k_{\mathrm{c}}$ is amplification factor of the amplifier $14, k_{\mathrm{p}}$ is the coefficient of the correction component of the cross-couplingsignal. In the process of the simulation of the mechanotronic hydraulic drive operation the signal of the cross-coupling $U_{2}$ was supplied by the controller to the regulated throttle valve 6 with the delay $\Delta T_{1}$.

For the belt conveyor of the mobile machine operating in the mode of variable load flows, the built-in hydraulic drive, sensitive to load changes is developed [15], its construction diagram is shown in Fig 3a.

Basic elements of the built-in hydraulic drive construction is the housing of the drum 1 , where the drive consisting of two separate hydraulic motors - principal motor 2 and additional motor 3, is built-in, transmission mechanism, consisting of the pinion 4 , intermediate 5 and crown 6 toothed wheels. The housing of the drum 1 is mounted on the compound axle, consisting of two half-axles 7 and 8 , connected to the housing of thetransmission mechanism. The control device 9 in the form of the indirect action valve is installed in one of the radial channels of the half-axle 7 for the supply of the working fluid to the hydraulic motors 2 and 3. The control device (Fig. 3b) contains the valve of the first stage with the conical-cylindrical gate 10 , which is pressed by the spring 11 to the seat 12 , mounted in the housing 13 and regulating screw 14 for the adjustment for the preset pressure.

The valve of the second stage - tubular slide valve 15 is pressed by the spring 16 to the seat 17 . The input of the additional hydraulic motor 3 in case of the switched off control device 9 is connected with the drain by the means of the relief valve 18 .

The buil-in hydraulic drive operates in the following way. If the pressure at the input in the hydraulic system does not exceed the regulating pressure of the control device 9, then the torque at the drum housing 1 is transferred from the shaft of the main hydraulic motor 2 on across the drive gear 4 , intermediate 5 and crown 6 totothed wheels.

In case of the sudden load increase the pressure at the input of the hydraulic system reaches the value $p_{2}$, that exceeds the nominal $p_{1}$,control device 9 is activated. Conical-cylindrical gate 10 is shifted relatively the seat 12 and the working fluid arrives to the drain across the hole 19. At the same time the pressure drop occurs at the throttle valve 20 . As a result, the tubular slide valve 15 shifts in the housing 21 together with the rubber seal ring 22 relatively the seat 17 to the left. The working fluid aross the hole 23 , hydraulic tube 24 arrives to the working chamber of the additional hydraulic motor 3 , switching it on in parallel to the principal hydraulic motor 2 . Throttle valve 25 is damping the tubular slide valve 15 , increasing the dynamic stability of the control device. Besides it forms the valve pot (between the throttle valve 25 and the end face of the tubular slide valve 15), optimal value of its flexibility provides necessary transient characteristics of the valve. The throttle valve 25 does not influence the amplification factor by the losses of the first stage valve and does not worsen the static characteristics of the control valve. As a result of the interaction of the working fluid with the rotor elements of the hydraulic motors 2 and 3 the rotation of their output shafts takes place. The torque from these hydraulic motors across the driving gear 4 intermediate toothed wheels 5 , crown wheel 6 is transferred to the drum housing 1 . Having lost the energy, the working fluid across the output holes of the hydraulic 
motors 2 and 3, pipelines 26 and 27, accordingly, radial 28 and axial 29 channels, located in the half shaft 8 , arrives to the drain.

For the stable operation of the hydraulic drive, without vibrations, the characteristic of the control device must correspond to the graphic dependence shown in Fig. 4 (22). Such dependence of the valve opening on the pressure at its input is provided by the construction of the developed control device.

Theoretical studies of the dynamic processes in non-stationary operation modes of the hydraulic drive operation were carried out on the base of the developed mathematical model [14].

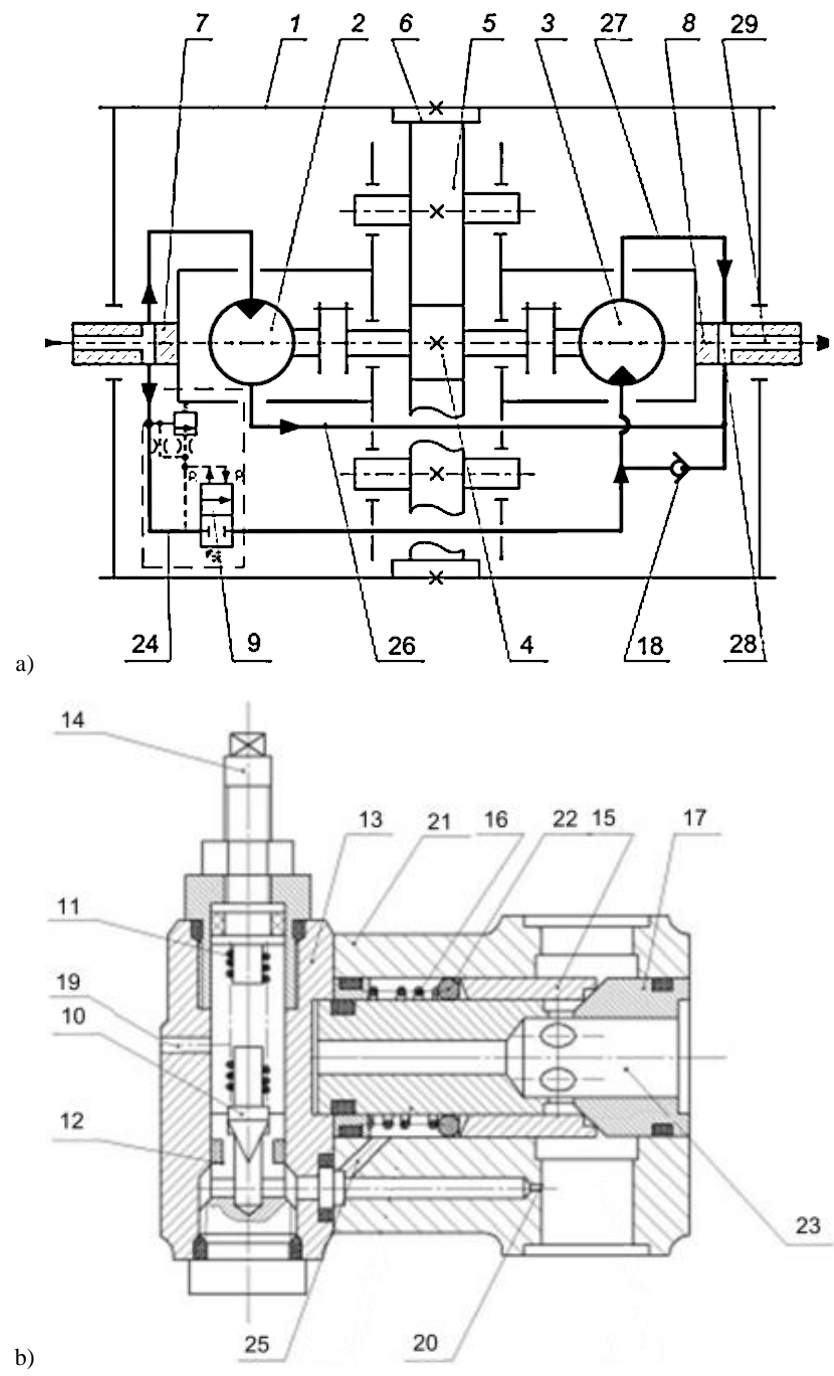

Fig. 3. Construction diagram of the built-in conveyor hydraulic drive, sensitive to the load change

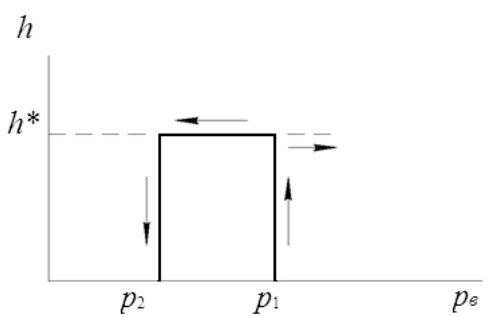

Fig. 4. Dependance of the value of the control drive opening on the pressure at the input of the hydraulic system

For the receiving conveyor of the clamp former K-65M253-K the construction [19] and technical documentation of the built-in hydraulic drive was developed, the construction diagram of the drive is shown in Fig. 5.
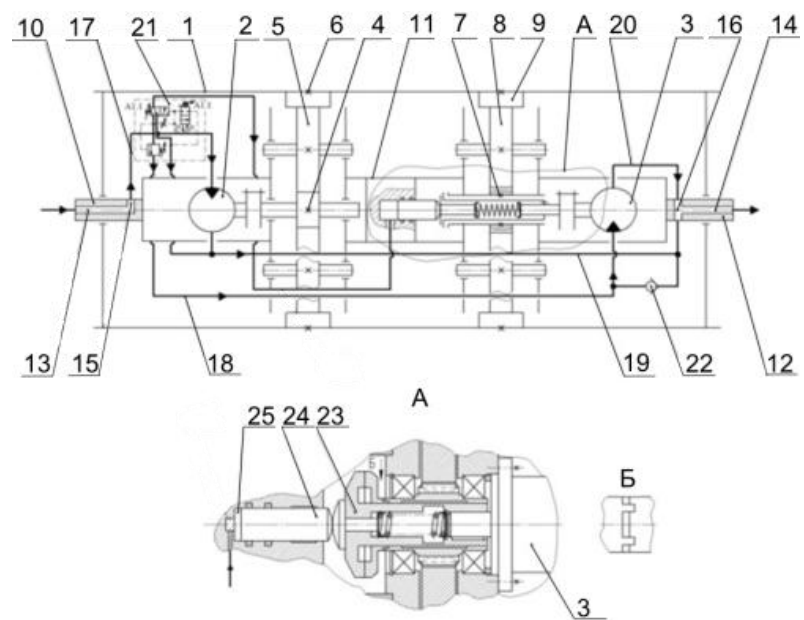

Fig. 5. Construction diagram of the buil-in hydraulic drive of the receiving conveyor of the clamp former $K-65 M 253-K$

The efficiency of the driveoperation is provided [17] applying in it the developed control system with the friction clutch for the switchingof the additional hydraulic motor. To reduce the resistance forces during the start of the addition hydraulic motor the control device of such system operates in such mode: first, with the small time delay the shaft displacement of the additional hydraulic motor occurs, then the friction clutch of the driving gear pinion is activated.

The controlled hydraulic electric cylinder motor contains the housing of the drum 1 , where the drive is buil-in, the drive is realized in the form of two separate hydraulic motors - main 2 and addition 3, and two transmission mechanisms. Each of them consists of the driving gears 4 and 7, intermediate 5, 8 and crown 6 and 9 gear wheels. The housing of the drum 1 is mounted on the axle, consisting of three parts $10,11,12$. For the supply and drain of the working fluid to the hydraulic motors 2 and 3 in the middle of the left and right parts of the axle 10 and 12 the axial passages 13 and 14 are made. They are connected with the working channels of the hydraulic motors 2 and 3 by means of radial channels 15 and 16,as well as pressure pipes 17 and 18 and drainage pipeline 19 and 20. In the pressure pipeline 17 the control device 21 is installed. The input of the additional hydraulic motor 3 , if the control unit 21 is switched off, is connected with the drain across the non-return valve 22 .

The control unit 21 is realized in the form of the two-stage valve, provided with the functions of the hydraulic distribution valve.

In the second transmission mechanism the friction coupling 23 is installed betvean the shalt of the additional hydraulic motor 3 and driving gear 7, its left half coupling across the cone has the contact with the end spherical surface of the pressing plunger 24 . It is mounted in the greater diameter of the central stepped hole, realized on the right side of the middle part 11 of the axel. Flat surface of the pressing plunger forms the cavity 25, connected with the cavity of the smaller diameter.

At nominal load on the working element of the conveyor the main hydraulic motor 2 operates, this motor by means of the transmission mechanisms puts in motion the body of the drum 1 . At sudden increase of the load, the value of which corresponds to the values of "opening" pressure, control unit 21 starts operation.

First the switching on of the additional hydraulic motor 3 occurs, then friction coupling 23 starts its operation, and the torque from the shalf of the additionalhydraulic motor 3 is transferred across the transmission mechanism to the body of the drum 1.

After load reduction on the working element of the conveyor to the value that corresponds to "closing" pressure, control unit 21 is actuated, it disconnects from the supply the additional hydraulic motor 3 . 
For studying the mutual impact of the parameters of the builtin hydraulic drive of the receiving conveyour with the control system and spring-inertial characteristics of its transporting part mathematical model, consisting of the equations, which describe the motion of the transport and drive parts of the conveyor and the switching control system of the additional hydraulic motor [24] is developed.

\section{Results of the study of the hydraulic automation equipment of the mobile machines with variable loading working elements}

The studies of the adaptive hydraulic drive of the manipulator determined that the oscillation of the hydraulic drive considently decreases from 8-10 oscillations to 2-4 oscillations in the transient process, depending on its operation modes. The value of the readjustment decreases on the value of up to $40 \%$ and does not exceed $30 \%$, at the operation of the manipulator of $7000 \mathrm{~N}$ carrying capacity.

Adaptive hydraulic drives provides high degree of the stabilization of motion speedv of the actuating mechanism if the $\operatorname{loadF}_{\mathrm{n}}$ changes. This enables to forecast better the motion of the actualingmechanism in the operation process, minimize the amount of the necessary motions when the manipulator is pointed on the object. The degree of the stabilization is evaluated by the dependence of the flow $Q$,that arrives to the hydraulic cylinder on the pressure value $\mathrm{p}_{\mathrm{c}}$ at the input in the hydraulic cylinder (Fig. 6). If the pressure value $p_{\mathrm{c}}$ changes in the range of $(0 \ldots 16) \mathrm{MPa}$, the change of $Q$ flow depends on the set value $Q$ and changes in the range from $3 \%$ to $6 \%$ at the pressure drop value on the proportional hydraulic distribution valve $1.5 \mathrm{MPa}$.

The transition on the value of the pressure drop of $1.0 \mathrm{MPa}$ increases the effort of the value $Q$ chang from $5 \%$ to $10 \%$.

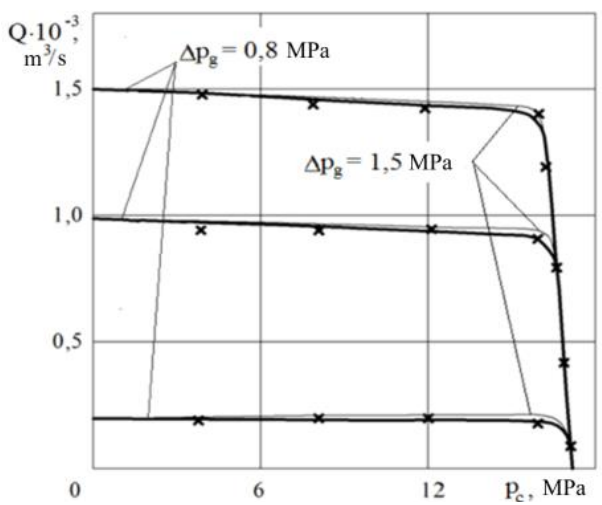

Fig. 6. Dependence of $Q$ on the pressure $p_{c}$ value at the input in the hydraulic cylinder

The important index of the manipulator operation quality is the pointing accuracy of the clamp on the object which determines the productivity of the nachineiperation stabilization of the manipulator modion speed allaws to increase the accuracy of the clamp pointing on the object [12]. Stady of the manipulator pointing accuracy, using the developed adaptive hydraulic drive is carried aut. The research is performed on the stand and using the technical,described in [12].

Fig. 7. shows the distribution of the results of the manipulator position measurements while directing it on the object. The results of the mensurements are in the range of $(37 \ldots 43) \cdot 10^{-2} \mathrm{~m}$. The obtained distribution law is close to normal. Mean square error of the manipulator position deviation is $\sigma_{1}=1.02 \cdot 10^{-2} \mathrm{~m}$ and the distance between the middle of the field for the manipulator pointing and the arithmetic mean value of the manipulator position $\overline{\mathrm{x}}=40.3 \cdot 10^{-2}$ mis $\Delta x_{1}=0.42 \cdot 10^{-2} \mathrm{~m}$.

The obtained results of measurements allow to assess the accuracy of the manipulator pointing on the object as such that allows to minimize the amount of motions in the operation cycle and increase the performance of the machine.

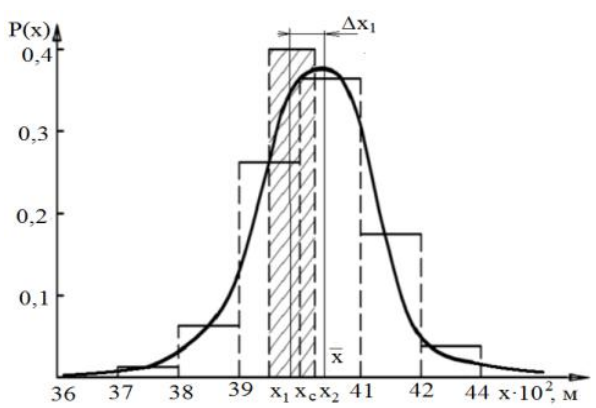

Fig. 7. Determination of the manipulatot pointing accuracy on the abject

At the stepped change of the momentM 1 value from $200 \mathrm{Nm}$ to $800 \mathrm{Nm}$ (Fig. 8) the transient process in the branch, which feeds the hydraulic cylinder, 3 occurs more dynamically with large readjustment by the pressure $\mathrm{p}_{\mathrm{c} 2}$ value.

The value of the delay changed in the process of the research in the range of $\Delta T_{1}=(0.005 \ldots 0.06)$ sec. The value of $k_{\mathrm{p}}$ coefficient of the correction component of the cross coupling signal varied in the range of $k_{\mathrm{p}}{ }^{\prime}=(40 \ldots 320) \cdot 10^{-4} \mathrm{sec}$.

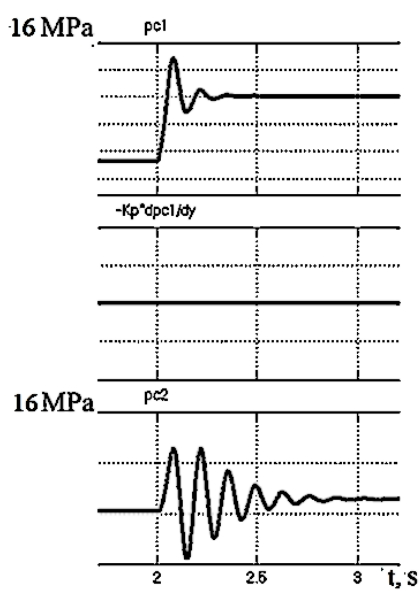

Fig. 8. Transient process in the adaptive hydraulic drive if the correction of the cross communication is missing

At the change of the delay value $\Delta T_{1}$ of the transient coupling signal of more than $0.04 \mathrm{sec}$. and less than $0.02 \mathrm{sec}$. the readjustment in the adaptive hydraulic drive increases (Fig. 9)

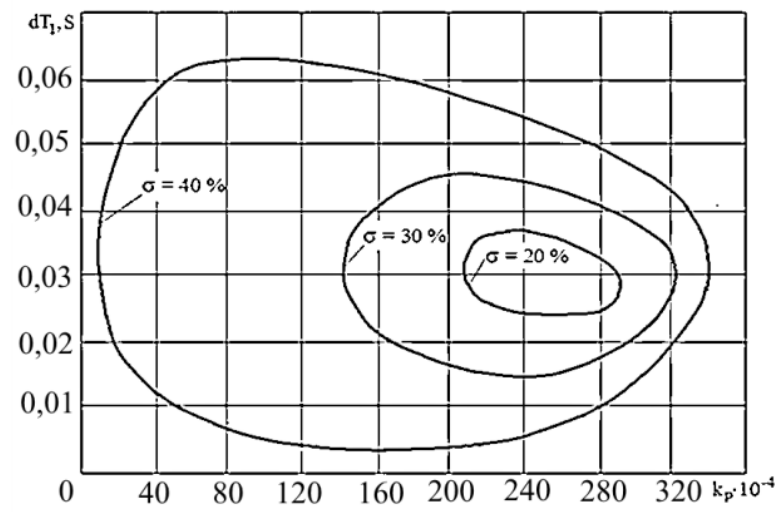

Fig. 9. Impact of the delay time $\Delta T_{1}$ and the correction component coefficient $k_{p}$ on the value of the readjustment in the adaptive hydraulic drive

At values of $\Delta T_{1}=(0.025 \ldots 0.04)$ sec. readjustment $\sigma=20 \%$ may be provided. For this purpose it is necessary to select the value $k_{\mathrm{p}}$ from the range $k_{\mathrm{p}}=(200 \ldots 280) \cdot 10^{-4} \mathrm{sec}$. Change of the coefficient $k_{\mathrm{p}}$ value of less than $200 \cdot 10^{-4}$ sec. and the greater value $k_{\mathrm{p}}=280 \cdot 10^{-4} \mathrm{sec}$. leads of the increase of the readjustment value $\sigma$. The selection of the rational values of $k_{\mathrm{p}}$ and $T_{1}$ provides the deacrease of the regulation time $t_{\mathrm{p}}$ and readjustment value $\sigma$ by the pressure $\mathrm{p}_{\mathrm{c} 2}$ at the input in the hydraulic cylinder 3 . 
Fig. 10 shows the transient process in the adaptive hydraulic drive, calculated by the mathematical model if the correction of the cross coupling signal is available.

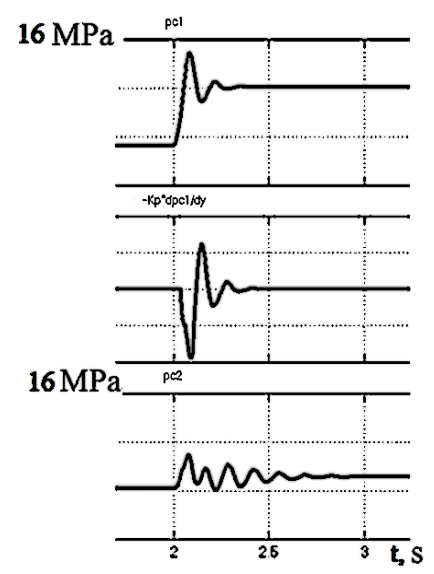

Fig. 10. Transient process in the adaptive hydraulic drive on case of the cross coupling correction

At the values of the correction component coefficient $k_{p}=250 \cdot 10^{-4} \mathrm{sec}$. and correction component delay $\Delta T_{1}=0.02 \mathrm{sec}$. the regulation time is $\mathrm{t}_{\mathrm{p}}=0.9 \mathrm{sec}$. and the readjustment value does not exceed $50 \%$. For the simultaneous decrease of the regulation time $t_{p}$ and readjustment value $\sigma$ on the change of the coefficient $k_{\mathrm{p}}$ and delay value $\Delta T_{1}$ the optimization nproblem must be solved.

The application of the adaptive regulator in the hydraulic drive of the small-size drilling installation enables to provide its operation in the semiautomatic mode.

The operation modes will vary depending on the type of the soil in which the drilling is performed.

The study of the dynamics of the hydraulic drive, sensitive to the load changes (Fig. 3) [18] was carried out on the base in the integration of the differential equctions of the developed mathematical model, applying the computer program, created on the base of Mathlab 13 package.

Analysis of the conditions of the hydraulically driven systems operation showed that the inertial loading, torsional shiffness, volume of the pressure pipe and the character of the load change influence the transient processes of the hydraulically driven installation [20].

Theoretical dependences regarding the character of the dynamic processes in the hydraulic drive, sensitive to load change have been obtained, one of these dependences is presented in Fig. 11: $p_{1}(t)$ - pressure in the main line of the main hydraulic motor; $p_{3}$ - pressure in the pipeline of the additional hydraulic motor after the activation of the control units; $Q_{1}(t), Q_{2}(t)-$ working fluidconsumptionacross the main and additional hydraulic motor, correspondingly; $n(t)$ - drum rotationfrequency; $M(t)$ - moment on the drum from the acting load.

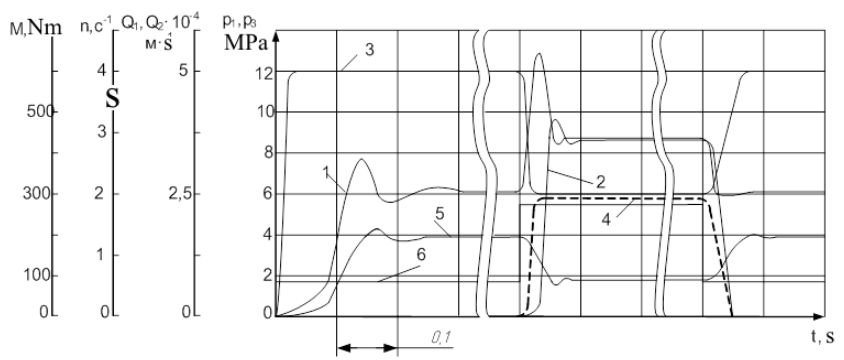

Fig. 11. Theoretical dependenciesp $p_{I}(t), p_{3}(t), Q_{I}(t), Q_{2}(t), n(t), M(t)$ (curves $1,2,3,4$, 5 , 6 correspondingly) at $p_{k 8}=12 \mathrm{MPa}$, torsional stiffnessc $c_{\varphi}=0.37 \cdot 10^{-3} \mathrm{Nm} / \mathrm{rad}$, ratio of the area of the conic-cylindrical gate $f_{3} / f_{4}=0.6$ and step-by-step load change

For the verification of the results of the theoretical studies and to specify the values of certain parameters, needed for carrying out the dynamic calculations experimental studies were performed.
Experimental and theoretical dependences of the impact on the time of the transient process of the start $t$ and the activation of the control unit to during its opening and closing, torsional stiffness of the mechanical part $c_{\varphi}$ (Fig. 12), inertia moment $I_{4}$ (Fig. 13), volume of the pressure cavity $V_{1}$ (Fig. 14) and the character of loads change $M(t)$ are constructed. It is determined that the 3 times increase of the torsional stiffness of the mechanical system of the conveyor causes the decrease of the duration of the transient processes of the start by $26 \%$ and control unit opening by $24 \%$, as well as the increase of the readjustment pressures $\Delta p_{1}$ by $80 \%$ and control unit opening $\Delta p_{\text {кв }}$ by $44 \%$; increase of the inertia load causes the increase of these parameters by $23 \%, 41 \%, 30 \%$ and $29 \%$,correspondingy; the increase of the volume of the pressure cavity $V_{1}$ increases the duration of the transient processes and reduces greatly the pressure readjustment. The comparison of the results of the theoretical and experimental research is carried out.

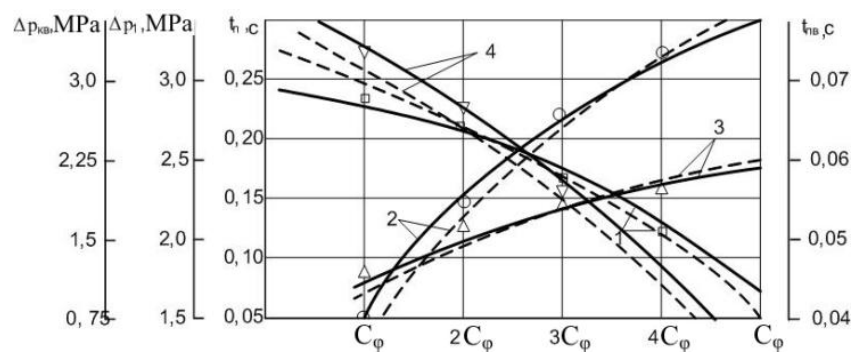

Fig. 12. Graph of the dependences $t_{n}\left(c_{\varphi}\right), \Delta p_{l}\left(c_{\varphi}\right), \Delta p_{k s}\left(c_{\varphi}\right), t_{k e}\left(c_{\varphi}\right)$ (curves $1,2,3$ and 4 correspondingly) at $p_{\mathrm{rg}}=12 \mathrm{MPa}$, torsional stiffness $c_{\varphi}=0.37 \cdot 10^{3} \mathrm{Nm} / \mathrm{rad} ; \mathrm{f}_{3} / \mathrm{f}_{4}$ $=0.6$ and step-by-step change of the resistance moment $M_{o}$ from $87 \mathrm{Nm}$ to $280 \mathrm{Nm}$ (-- theoretical, - experimental)

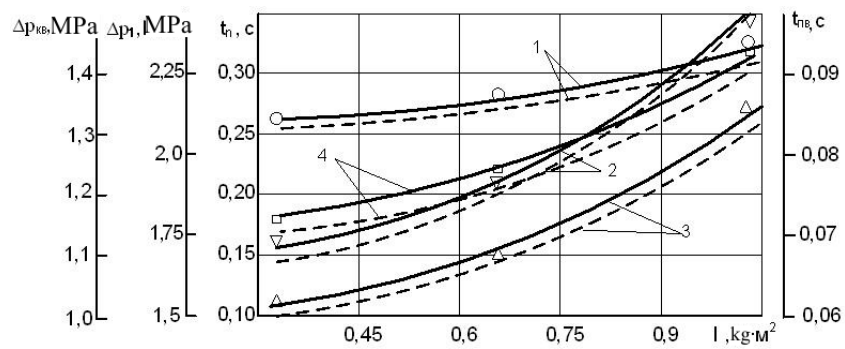

Fig. 13. Graph of the dependences $t_{n}(I), \Delta p_{I}(I), \Delta p_{K \varepsilon}(I), t_{k 8}(I)$ (curves $1,2,3$ and 4 correspondingly) at $p_{\kappa \varepsilon}=12 \mathrm{MPa}$, torsional stiffiness $c_{\varphi}=0.37 \cdot 10^{-3} \mathrm{Nm} / \mathrm{rad} ; f_{3} / f_{4}$ $=0.6$ and step-by-step change of the resistance moment $M_{o}$ from $87 \mathrm{Nm}$ to $280 \mathrm{Nm}$ (-- theoretical, - experimental)

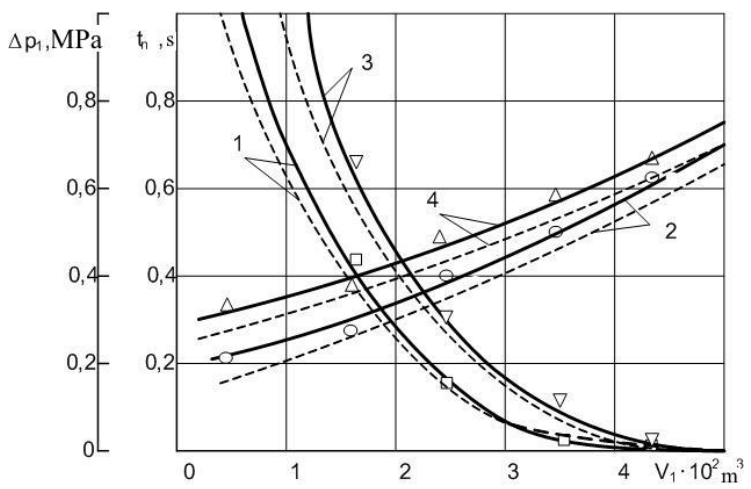

Fig. 14. Graph of the dependences $\Delta p_{I}\left(V_{I}\right), t_{n}\left(V_{l}\right)$ (curves 1, 2 correspondingly) if the resistance moment is missing and $\Delta p_{I}\left(V_{l}\right), t_{n}\left(V_{l}\right)$ (curves 3,4 correspondingly) at $p_{\kappa в}=12 \mathrm{MPa}$, torsional stiffness $c_{\varphi}=0.37 \cdot 10^{-3} \mathrm{Nm} / \mathrm{rad} ; f_{3} / f_{4}=0.6$ and step-by-step change of the resistance moment $M_{o}$ from $87 \mathrm{Nm}$ to $280 \mathrm{Nm}$ (curves 1, 2, 3 and 4 correspondingly) (--- theoretical, - experimental)

Theoretical investigations of the hydraulic drive of the clamp former receiving conveyor with the control system of the additional hydraulic motor switching were carried out. The solution of the system of the non- linear differential equations of the mathematical model was performed by means of the programming package Matlab Simulink. The study of the dynamic characteristics for the driving and transporting parts of the conveyor was performed on the base of the analysis of the 
transient processes graphs $M(t), p_{\mathrm{n}}(t), p_{1}(t), p_{2}(t), x(t), y(t), z(t)$ (Fig. 15). The moment on the drum changed from the nominal value of $5 \mathrm{kN} \cdot \mathrm{m}$ to the overload value of $12 \mathrm{kN}$.m. Overload mode is characterized by three phases of the transient processes: the first - switching on of the additional hydraulic motor $\left(0.11 \mathrm{sec}<t_{p 1}<0.15 \mathrm{sec}, 15 \%<\Delta p_{1}<45 \%\right)$; the second operation of the drive with two hydraulic motors $\left(0.05 \mathrm{sec}<t_{p 2}<0.12 \mathrm{sec}, 4 \%<\Delta p_{2}<12 \%\right)$; the third - load decrease and disconnection of the additional hydraulic motor $\left(0.9 \mathrm{sec}<t_{p 3}<0.17 \mathrm{sec}, 20 \%<\Delta p_{3}<55 \%\right)$.

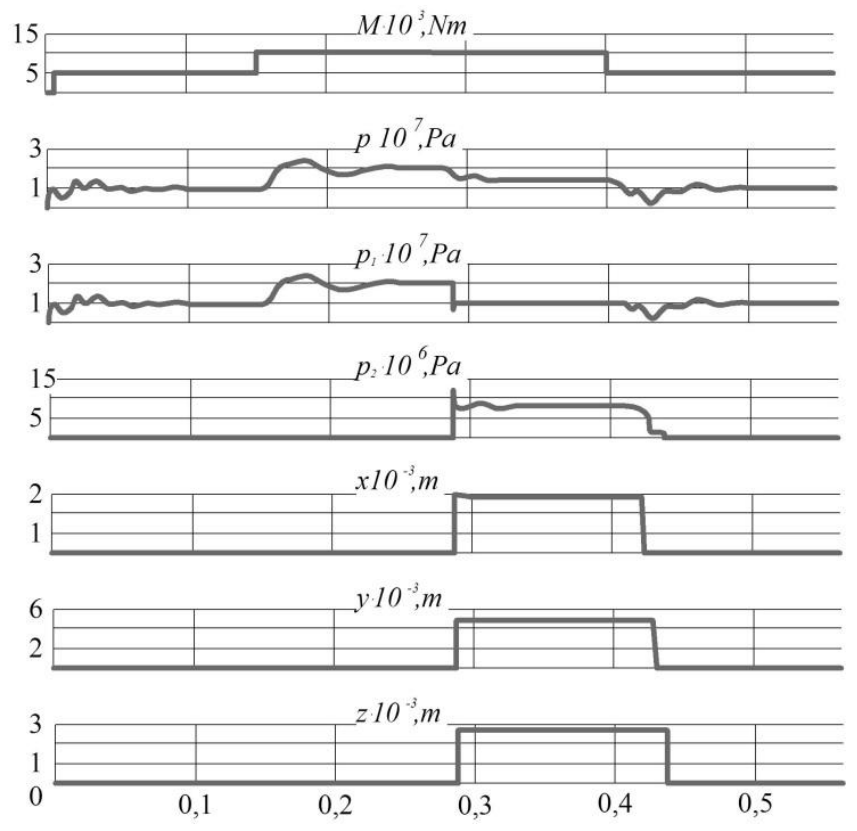

Fig. 15. Theoretical graphs of the transient processes of $M(t), p n(t), p 1(t), p 2(t), x(t)$, $y(t), z(t)$ change

For each of the above-mentioned phases of the transient process the impact of the pressure increase value $\Delta p$ in the pressure pipe, torsional stiffness $c_{f}$ and transmission mechanism damping, aggregate moment of the drum I $b$ inertia, static $E_{s}$ and dynamic $h_{s}$ belt elasticity modulus, conveyor length $L_{s}$ was analyzed (Fig. 16, Fig. 17)

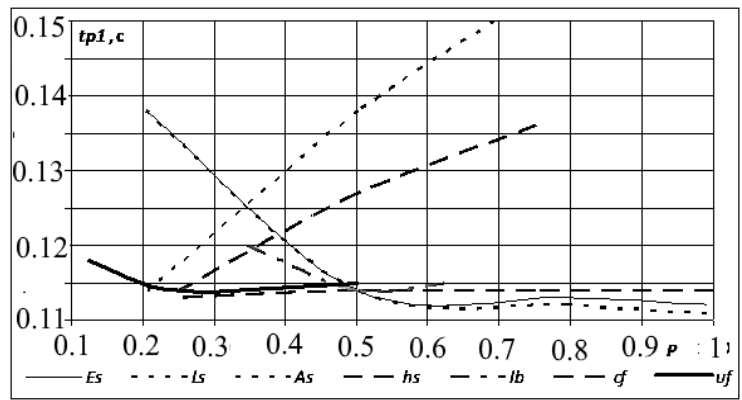

Fig. 16. Impact of the parameters of the driving and transporting parts of the conveyor on the transient process time for the first phase of the overloading

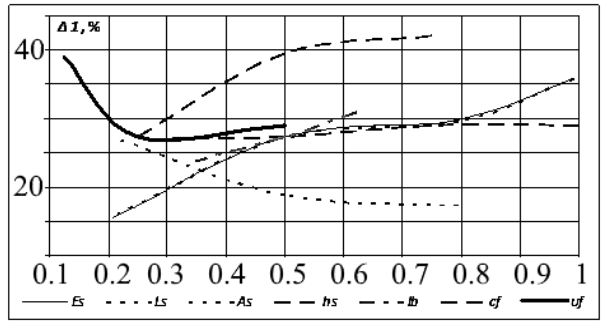

Fig. 17. Impact of the parameters of the driving and transporting parts of the conveyor on the pressure readjustment for the first phase of the overload
The obtained dependences will allow to optimize the duration of the transient processes $t_{p}$ and the pressure increase $\Delta p$ (and the dynamic component of the loading in the belt) at the expense of the selection of the above -mentioned parameters.

\section{Conclusions}

The research proves the efficiency of using the hydraulic automatic devices for the improvement of the technical-economic indices of the operation elements of the mobile machines.

The operation of the adaptive regulator at the optimal valve of the greatly decreases the readjustment value and regulation time at the expense of the intensive quench of the drive oscillations in the transient processes. It is determined that the value of coefficient depends on the operation modes of the hydraulic drive, namely, on the value of the working fluid supply $Q_{\mathrm{n}}$ to the hydraulic motor and pressure value $\mathrm{p}_{\mathrm{c}}$ in the hydraulic drive.

The operation of the adaptive hydraulic drive in the small- size drilling installation provides the increase of the performance and decreases the readjustment by $30-60 \%$, depending on the operation modes that reduces the dynamic loading on the elements of the hydraulic drive.

The suggested hydraulic automation facilities provide troublefree operation of the conveyor in the conditions of varying useful resistance forces and decrease of the dynamic impact in the transporting element

Application of - the control system with the valve- type device, having the functions of the distributor and the friction clutch for the disconnection of the additional hydraulic motor of the built-in hydraulic drive enabled to improve its dynamic characteristics.

Compatibility of the considered adaptive drives of the technological and mobile machines [21] has been proved by the comparative economic calculations.

\section{References}

[1] Bing X., Ruqi D., Junhui Z., Min C., Tong S.: Pump valves coordinate control of the independent metering system for mobile machinery. Automation in Construction 2015, 98-11.

[2] Busquets E., Ivantysynova M.: Toward Supervisory-Level Control for the Energy Consumption and Performance Optimization of DisplacementControlled Hydraulic Hybrid Machines. Mobile Hydraulics Paper 10(2)/2016, 163-174.

[3] Cheng G., Shuangxia P.: Adaptive sliding mode control of electro-hydraulic system with nonlinear unknown parameters. Control Engineering Practice 2008 $1275-1284$

[4] Du C. Variable Supply Pressure Electrohydraulic System for Efficient Multiaxis Motion Control : A thesis submitted for the degree of Doctor of Philosophy University of Bath Department of Mechanical Engineering. University of Bath November 2014.

[5] Finzel R.: New Electro-Hydraulic Control Systems for Mobile Machinery. Fluid Power and Motion Control 2008, United Kingdom 311-321.

[6] Forental V., Forental M., Nazarov F.: Investigation of Dynamic Characteristics of the Hydraulic Drive with Proportional Control. Procedia Engineering. International Conference on Industrial Engineering (ICIE-2015) 129/2015, 695 701.

[7] Kotlobay A. Ya., Kotlobay A. A., Tamelo V. F.: Hydraulic assemblies of drive systems of the road equipment for road-building machines. Science and Technology 15(1)/2016, 69-77.

[8] Kozlov L: Energy-saving mechatronic drive of the manipulator. Buletinulinstitutuluipolitehnic Din Iasi. Tomul LVII (LXI), Fasc. 3/2011, 231239.

[9] Kozlov L.G., Burennikov Yu.A., Pylyavets V.G., Korinenko M.P., Lizhov O.V.: Ensuring the stability of the mechanotronic hydraulic drive. Journal of Mechanical Engineering and Transport 1(9)/2019.

[10] Kozlov L.G., Polishchuk L.K., Piontkevych O.V., Korinenko M.P., Horbatiuk R.M., Komada P., Orazalieva S., Ussatova O.: Experimental research characteristics of counterbalance valve for hydraulic drive control system of mobile machine. PrzegladElektrotechniczny 95(4)/2019, 104-109.

[11] Kozlov L.G.: Mechatronhydrosystem of a mobile machine. Bulletin of the Volodymyr Dahl East-Ukrainian University 6/2012, 22-30.

[12] Kozlov L.G.: Scientific foundations for designing the systems of manipulator hydraulic drives with an adaptive neural network-based controllers for mobile working machines. Thesis for the scientific degree of Doctor of Science (Engineering). National Technical University of Ukraine Kyiv Polytechnic Institute, Kyiv 2015.

[13] Lauhoff H.: Speed Control on Belt Conveyors - Does it Really Save Energy? Bulk Solids Handling 22(6/)2005, 368-377. 
[14] Polischuk L.K., Adler A.O., Sturma A.L.: Control device for hydraulic drive with variable load on the working body. Bulletin of the Volodymyr Dahl East Ukrainian National University 3(109)/2007, 195-200.

[15] Polischuk L.K., Adler A.O.: Embedded hydraulic drives of conveyors with a flexible pulling body, sensitive to load change. VNTU, Vinnitsa 2010.

[16] Polischuk L.K.: Dynamics of the built-in hydraulic drive of conveyors of mobile machines. VNTU, Vinnytsa 2018.

[17] Polishchuk L., Kharchenko Y., Piontkevych O., Koval O.: The research of the dynamic processes of control system of hydraulic drive of belt conveyors with variable cargo flows. Eastern-European Journal of Enterprise Technologies 2(8)/2010, 22-29.

[18] Polishchuk L.K., Adler O.O., Malyarchuk A.O.: Influence of the load change characteristics on the dynamics of the integrated hydraulic drive. Machine Science 11/2009, 31-35.

[19] Polishchuk L.K., Koval O.O.: Control system of a hydraulic drive of a belt conveyor with variable load. The Bulletin of the Vinnytsia Polytechnic Institute 2(191)/2015, 131-136

[20] Polishchuk L.K., Kozlov L.G., Piontkevych O.V., Horbatiuk R.M., Pinaiev B., Wójcik W., Sagymbai A., Abdihanov A.: Study of the dynamic stability of

\section{Prof. Leonid Polishchuk}

e-mail: leo.polishchuk@gmail.com

Works at the Faculty of Mechanical Engineering and Transport in Vinnytsia National Technical University. Head of the Department of Industrial Engineering.Conducts research on problem related to the dynamics and diagnostics of driving systems and metal support structures of heavy lifting and transportation machinery. The author of more than 200 scientific papers, including two monographs.

ORCID ID: 0000-0002-5916-2413

\section{Prof. Leonid Kozlov}

e-mail: osna2030@gmail.com

Head of the Department of Technology and Automation of Machine Building of Vinnytsia National Technical University (Ukraine). Specializes in hydraulic drives, hydroautomatics and mechatronics. The author of more than 180 scientific papers.Developments by Kozlov L.G. marked with 3 gold medals at international exhibitions in Yassi (Romania).

\section{ORCID ID 0000000196521270}

\section{Prof. Yuri Burenniko}

e-mail: yu.burennikov@gmail.com

Dean of the Faculty of Mechanical Engineering and Transport of Vinnytsia National Technical University (Ukraine).Specializes in the field of hydraulic and hydroautomatics. The author of more than 140 scientific papers, including two monographs.Developments by BureniknikovaYu.A. marked with 3 gold medals at international exhibitions in Yassi (Romania). Honored Worker of Education of Ukraine
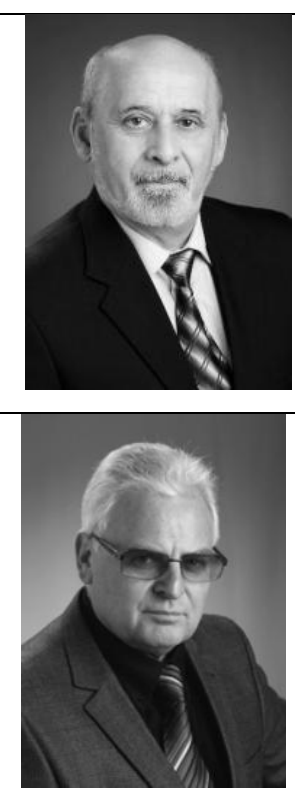

the belt conveyor adaptive drive. Przeglad Elektrotechniczny 95(4)/2019, 98 103.

[21] Scherer M., Geimer M., Weis B.: Contribution on Control Strategies of FlowOn-Demand Hydraulic Circuits. The 13th Scandinavian International Conference on Fluid Power June 3-5 2013, Sweden, 531-540.

[22] Shakhmeister L.G., Dmitriev V.G.: Theory and calculation of belt conveyors Engineering, Moscov 1978.

[23] Sidorenko V.S., Grishchenko V.I., Rakulenko S.V., Poleshkin M.S.: Adaptive hydraulic drive with volumetric regulation of the tool feed of a technological machine. Bulletin of Donetsk State Technical University 2/2017, 88-98.

[24] Stamm von Baumgarten T.: A novel system layout for extended functionality of mobile machines. Fluid Power and Motion Control 2008, United Kingdom, 13 25.

[25] Wheeler C.A.: Evolutionary Belt Conveyor Design - Optimizing Coasts. Bulk Material Handling by Conveyor Belt. 7, Littleton, Colorado 2008.

[26] Zaika V.T.: Influence of an adjustable drive on cargo flows and energy efficiency of the system of mine conveyor transport. Science bulletin of National Mining University $3 / 2015,82-88$.

\section{Prof. Vasil Strutinskiy}

e-mail:kvm_mmi@ukr.net

Professor of the Department of Designing Machines and Machines of the National Technical University of Ukraine "Kyiv Polytechnic Institute named after Igor Sikorsky". Specializes in the development of the theory of designing machine tools, robotic systems and machines. The author of more than 500 scientific papers, including 12 monographs. Honored Worker of Science and Technology of Ukraine.Vice-President of the Association of Industrial Hydraulics and Pneumatics (Ukraine).

ORCID ID0000-0001-5533-9915

M.Sc. Valerii Kravchuk

e-mail: kravchuk.vntu@gmail.com

Postgraduate student at the Department of Industrial Engineering at Vinnytsia National Technical University. Specializes in the field of hydraulic drives and means of automation of technological and mobile machinery. The author of 10 scientific papers

ORCID ID: 0000-0003-4815-7384
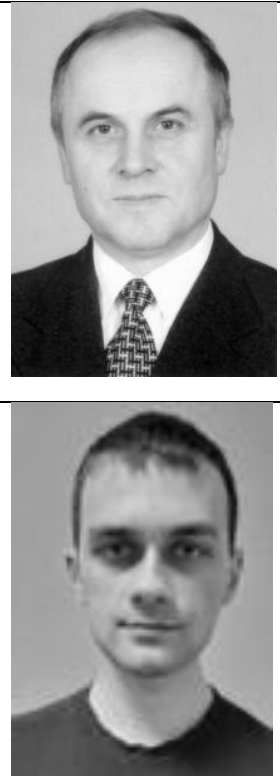

otrzymano/received: 15.05.2019 przyjęto do druku/accepted: 15.06.2019 